\title{
The Windmill of Learning Processes: A learning and teaching tool for student nurses and mentors
}

\author{
Linda Kragelund * \\ The National Centre of Competence Development, The Danish School of Education, Aarhus University, Tuborgvej 164, 2400 Copenhagen NV, Denmark
}

\section{A R T I C L E I N F O}

Article history:

Accepted 17 March 2010

\section{Keywords:}

Clinical placement

Learning processes

Nursing education

Pedagogical tool

Psychiatric nursing

\begin{abstract}
S U M M A R Y
This article presents a new approach to student nurses' learning from their interaction with psychiatric patients. Using the approach can enable students and mentors to exploit students' learning opportunities, and help students to get the most out of their clinical placement in a time, where that part of the nursing education has been reduced in some countries as e.g. Denmark.

The approach is presented through a model termed the 'Windmill of Learning Processes', which draws on empirical data from a qualitative investigation with an explorative and descriptive design, and on the theoretical concepts of 'disjuncture', and 'everyday life activities'.

'Disjuncture' is defined as a situation in which there is disharmony between a person's experiences and the current situation. In such a situation there is potential for learning. My analysis of the empirical data led to the identification of a new concept, which I have labelled 'collective not-conscious disjuncture'. This is when the student and the mentor are both unaware that the student is operating in a potential learning situation. 'Everyday life activities' are seen as activities that are known to succeed in specific situations, because they have done so in similar situations. I have expanded upon the concept to define another phenomenon, which I have coined 'pseudo-everyday life activities'. These closely resemble everyday life activities, but take place in a psychiatric context.
\end{abstract}

(c) 2010 Elsevier Ltd. All rights reserved.

\section{Introduction}

The Danish Nursing Education was transformed from vocational training to a Bachelor's Degree in 2002. The clinical placement component of the training was reduced, while the objectives of the clinical placement were expanded (Ministry of Education, 2001). This made it important to investigate how the clinical part of the student nurses' (students') training could be optimised. In this regard, I completed a research project about student nurses' learning processes in their interaction with psychiatric patients during their clinical placement in psychiatry. It was a qualitative investigation with an explorative and descriptive design (Kragelund, 2006). In this article I focus on the results of the study represented by a model termed the 'Windmill of Learning Processes' (the 'Windmill model'). The Windmill model offers a new way of looking at, and talking about, student nurses' learning in clinical practice. Furthermore, it provides a discourse to talk about the learning opportunities that students and mentors are unaware of.

It is argued that if student nurses and mentors use the Windmill model as a learning and teaching tool during the students' clinical placement, it is possible to optimise student nurses' learning opportunities and so make the clinical training more effective (Kragelund, 2007).

\footnotetext{
* Tel.: +4588 8899 65; fax: +4588 889922.
}

E-mail address: likr@dpu.dk.

\section{Background}

State-of-the-art

A state-of-the-art review of the prevailing literature on nursing education between 2002 and 2004 was undertaken. A variety of keyword combinations, e.g. 'nursing education', 'clinical education', 'clinical learning', 'learning in practice', 'learning processes', 'psychiatric nursing' and 'mental health nursing', were run through relevant databases (Medline, PsycInfo and CINAHL). A number of international nursing journals were also examined, as were individual article references. 300 pertinent articles were found: just under half dealt with student nurses' learning; 28 focused on the specific issue of students' learning during their clinical placement in psychiatry (Kragelund, 2006).

Student nurses' interaction and therapeutic relationships with patients

The main findings according to student nurses' learning during their clinical placement had to do with how they learn to interact and develop a therapeutic relationship with psychiatric patients, and barriers with regard to that (Lauder et al., 2002; Melrose and Shapiro, 1999; Morrissette, 2004; Munnukka et al., 2002; Rungapadichy et al., 2004; Tully, 2004). 
Students are interested in learning how to interact with and relate to patients, and regarding that they need mentors as positive rolemodels (Munnukka et al., 2002). However research shows that mentors sometimes act as 'poor role-models', which might have a negative influence on students' learning. Some students observed what they termed 'alleged malpractice', where the nurses did not get involved with the patients, lacked skills and showed a negative approach to care (Rungapadichy et al., 2004).

Students' chance of learning to interact and develop a therapeutic relationship with patients can be affected by factors such as how the learning possibilities are on the ward; if there is a space for students where they have an opportunity to talk about their experiences and get feedback (Morrissette, 2004); if students have mentors they can use as positive role-models (Munnukka et al., 2002); and students' own ability to interact with and relate to patients (Lauder et al., 2002).

Barriers in relation to learn to interact with and relate to patients are e.g. that the students feel fear, because they do not know how to care for patients (Melrose and Shapiro, 1999), or they feel stressed because they have to interact with the patients (Morrissette, 2004; Tully, 2004). This stress might make them withdraw from interaction with patients (Morrissette, 2004).

To sum up, student nurses are interested in interaction with patients and in developing a therapeutic relationship with them. To develop such skills they need positive role-models because they find the relationship with patients stressful and they are scared because they do not know how to take care of the patients. The mentors are not always able to give the students the learning possibilities they need to learn to interact with and relate to patients.

\section{Hospital wards as learning environments}

According to hospitals as learning environments the most important result in state-of-the-art is that student nurses need supportive and caring learning environments, with mentors who are interested in mentoring. Such learning environments give the students the opportunity to get the most out of their learning processes and to achieve the objectives of the clinical placement. Nevertheless, mentors do not always meet the students' needs, and the time spent in clinical practice is not always used effectively (Chan, 2002; Papp et al., 2003; Pearcey and Elliott, 2004; Saarikoski and Leino-Kilpi, 2002).

Important for students is a learning environment characterised by co-operation amongst staff and an atmosphere in which they are treated as colleagues. Students appreciate learning situations where they have a possibility to develop professionally and to learn the attitudes and moral understanding amongst nurses. In addition, students characterise a good clinical learning environment by how the ward lives up to the philosophy of good nursing, because if it does, it influences their learning in a positive way (Papp et al., 2003; Saarikoski and Leino-Kilpi, 2002). If students observe mentors act in conflict with the philosophy of good nursing or if they do not act as positive role-models, it affects the students learning negatively (Pearcey and Elliott, 2004). To summarise, students find their relationship with their mentor important for their learning and they appreciate a learning environment where they both have the opportunity to learn to act professionally and to learn about the values and norms on the ward (Chan, 2002; Papp et al., 2003; Saarikoski and Leino-Kilpi, 2002).

\section{Theoretical framework}

\section{Disjuncture}

Jarvis' concept of disjuncture offers a theoretical way of understanding the empirical phenomenon of 'non-routine situations', that is why I use disjuncture in the Windmill model. Briefly, Jarvis defines disjuncture as a social situation in which there is a disharmony between a person's experiences and the current situation the person is in (Jarvis, 1987, 2005). Jarvis is of the opinion that it is fundamental for human beings to try to create meaning in social situations. As long as there is harmony between our experience of a current situation and our construction of the meaning of that situation, we do not have to ask questions about meaning. In contrast, if we experience something unknown, we ask questions in order to re-establish meaning.

One of Jarvis' basic assumptions is that where there is disharmony between a person's experience and the social situation the person is in, there is potential for learning. This is disjuncture. Such situations are non-routine. According to Jarvis, disjuncture has three aspects:

1. Persons can experience disjuncture either in a current situation, or they can imagine future situations where there will be disjuncture in relation to their knowledge, skills and/or attitudes (Jarvis, 1987, 2005). In such situations, disjuncture is obvious to the persons themselves.

2. It is possible to talk about different degrees of disjuncture. They are related to what extent that it is routine or non-routine for a person to act in a certain situation. Jarvis says that as we get accustomed to certain actions, we move from performing in an experimental and creative way in novel situations, through performing repetitively, then routinely, and, finally, ritually and with a sense of alienation.

We perform creative and experimental actions in novel situations. At the other end of the spectrum lie the situations we take for granted. These are situations in which we act pragmatically and automatically. While there is still meaning for the person acting, it is done 'unconsciously'. There is harmony between the persons' experiences and their social situation. It is a routine (Jarvis, 1999).

There is a risk that actions which have become routine for a person, lead to ritualism. This is when the performer does not notice the nuances in situations. There is also a risk that persons acting ritually lose their humanity and come to act robotically (Jarvis, 1999).

Ritualism can deteriorate into alienation. This means that acts are performed without meaning for the person who is acting. The work is seen as boring and repetitive. It is worth noting that it may be difficult to judge whether an action is routine or non-routine for any individual. Many situations contain elements of both (Jarvis, 1992a, 1999). One of Jarvis' points is that professionals also learn in situations with routine actions, because they are able to ask questions both about their actions and the attitudes behind them. They are able to regenerate disjuncture (Jarvis, 1999).

3. It is a question of who is aware or unaware of the disjuncture. Is the person in the situation aware that it is non-routine? If not, are other people in the person's surroundings aware of this (Jarvis, 1987, 1992b, 2005)? Or does neither the person in question nor the surrounding people, realise that there is disjuncture?

I am developing this third aspect of disjuncture further, since it makes it possible to categorise student nurses' learning processes into four different types of disjuncture. That makes it likely for students and mentors to get aware of the learning possibilities on the ward, and for the students to get the most out of them. However first, I am explaining the concept of 'pseudo-everyday life activities'.

\section{Pseudo-everyday life activities}

Heller's concept of 'everyday life activities' is useful to understanding and analysing the content of student nurses' learning processes. Everyday life is regularly repeated, it happens over and over again, and it is structured by traditional norms and rules, which we do not question. Everyday life is cyclic, and it consists of 'everyday life activities', which are all the activities we perform without reflection. They are activities that we know will work in specific 
situations, because they have done so in similar situations. Examples are dressing, eating and shopping (Heller, 1970/1984).

There are many similar acts in psychiatric nursing. These include: making small talk in the sitting room; shopping for meals; meal preparation; eating; going for a walk; and playing cards (Kragelund, 2006). Everyday life in psychiatric wards has a cyclic rhythm, and the content is directed by norms and rules e.g. house rules, circadian rhythm plans, and weekly plans.

My research revealed that student nurses were frequently assigned to assist with such 'everyday life' tasks. Both student and mentor thought of these as routine for the student, when in fact the evidence showed the opposite. The students did not know how to act in such situations, and would often make mistakes or abandon the situations altogether. These activities are termed 'pseudo-everyday life activities' because they take place in the context of clinical psychiatry. Such activities are potential learning situations.

\section{Findings}

\section{Four types of disjuncture}

Student nurses' learning processes can be usefully categorised as one of four types of disjuncture, based on to whom it is obvious, and not obvious. This dichotomy can be juxtaposed with the binaries: individual versus collective, and aware of versus unaware of.

1. Individual versus collective refers to whether or not the student alone, that is individually, is aware or not, that a situation is nonroutine, or, in contrast to this, whether both the student and the mentor, that is collectively, are aware or not that the student is in a non-routine situation. Every situation/unit of analysis includes attention to three elements: beginning - interaction between student and patient - after play (Kragelund, 2006).

2. Aware of versus unaware of refers to whether or not the student and the mentor realise that a situation is non-routine for the student.

These four types of disjuncture form part of student nurses' learning processes, and are illustrated by Fig. 1. The top half of the Windmill model depicts situations where the student alone is either aware or not of being in a situation of disjuncture. This is called individual disjuncture. Conversely, the lower half depicts those situations where both the student and the mentor are either aware or not, that the student is in a non-routine situation. This is called collective disjuncture.

Collective conscious disjuncture (Fig. 1: lower left quadrant). There are situations where disjuncture is obvious to both the person, and to people in the person's surroundings (Jarvis, 1992b, 2005). Situations of collective conscious disjuncture include, by definition, individual

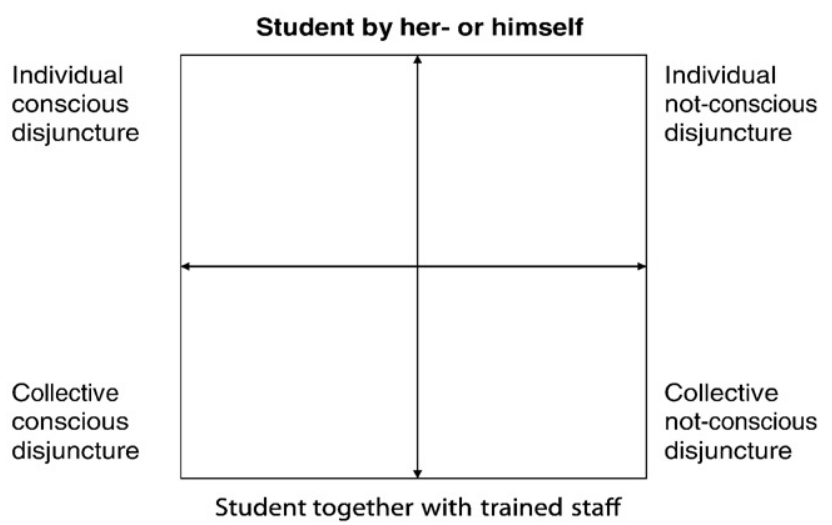

Fig. 1. The four types of disjuncture which are the basis of The Windmill of Learning Processes. conscious disjuncture. Collective conscious disjuncture occurs in situations where both students and mentors are aware that the situation is non-routine for the student.

Individual conscious disjuncture (Fig. 1: upper left quadrant) is characterised by situations where students are aware that these are non-routine.

Individual not-conscious disjuncture (Fig. 1: upper right quadrant). There are cases where persons are unaware of disjuncture. Jarvis describes two ways which can help the persons to realise this. Firstly, the persons can gain this awareness if they fail to achieve the expected result from the situation. Failing this scenario, they can reach awareness of the disjuncture if another person, such as a mentor, asks guided questions about the situation (Jarvis, 1987, 1992b, 2005).

Collective not-conscious disjuncture (Fig. 1: lower right quadrant) is the fourth type of disjuncture, and it is my further development of Jarvis' concept (Kragelund, 2006). Collective not-conscious disjuncture is a potential learning situation in which neither the student nor the mentor is aware that the situation is non-routine for the student. This is often a routine situation for the mentor. Consequently, mentors no longer ask questions about their own way of acting, neither in relation to the patients, nor in relation to their attitudes behind these actions. We can assume this is one of the reasons that such situations are not seen as potential learning possibilities for students.

Collective not-conscious disjuncture incorporates, by definition, individual not-conscious disjuncture, too. These four types of disjuncture form the underlying structure of the Windmill model, however it is also possible to categorise student nurses' learning processes in the overall content of the learning processes (Kragelund, 2006).

\section{The overall content of learning processes}

It is relevant to look at the content of student nurses' learning processes, because the students have to achieve certain objectives in order to pass their clinical psychiatry module. The objectives are described in the Danish University Colleges' curriculum. The content of learning processes build on the assumption: to become a nurse $=$ to learn to be a nurse + to learn to perform nursing. Learning to be a nurse and learning to perform nursing are two complementary elements of content. In addition to that, there is a third element: pseudo-everyday life activities, partly overlapping the other two (Kragelund, 2006). These three overall elements of content are graphically illustrated in Fig. 2.

Learning to be a psychiatric nurse can also be termed professional socialisation (Fig. 2: 'the waves'). The process of professional socialisation means that students acquire the unwritten attitudes and norms-and-rules of the field. They are embodied in the nurses' actions. The written objectives of the students' clinical placement in a psychiatric hospital unit contain nothing about professional socialisation per se, about values and attitudes in the field of psychiatry, and, in specific relation to that, nothing about attitudes towards psychiatric patients. Such objectives are hidden or unwritten (Kragelund, 2006). Potential learning possibilities in relation to professional socialisation may often be characterised by collective not-conscious disjuncture (Fig. 2: lower right quadrant). There are unexploited learning possibilities in relation to learning about attitudes and values in interaction with psychiatric patients (Kragelund, 2006). The students learn about attitudes and values primarily through observing mentors interacting with patients and through listening to mentors talking to each other about patients. Examples of unwritten norms-and-rules are: house rules about safety for patients and staff, e.g. that glass is not allowed on locked wards; where on the wards professionals are allowed to talk with patients about their personal problems; what attitudes professionals ought to have towards patients (Kragelund, 2006). 


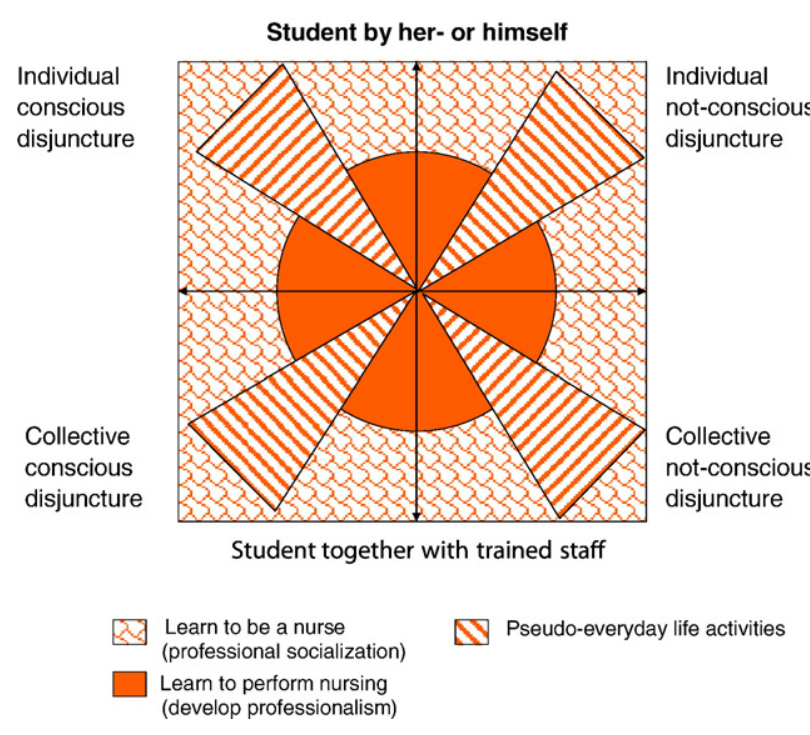

Fig. 2. The Windmill of Learning Processes.

Developing professionalism can also be termed 'learning to perform psychiatric nursing' (Fig. 2: the shaded circle). It refers to the acquisition of the necessary knowledge and skills in order to be able to perform psychiatric nursing professionally. The objectives of the students' clinical placement in relation to development of professionalism are explicit, and written down in the Danish University Colleges' curriculum (Kragelund, 2006). These types of learning processes can often be categorised as collective conscious disjuncture, both students and their mentors are aware that the student is in a non-routine situation (Fig. 2: lower left quadrant). In such situations, students can potentially learn something through their interaction with patients. Examples are: establishing, maintaining and ending contact with patients; containing patients' projections; setting limits for patients; and administering medicine (Kragelund, 2006).

The third element of content in the learning processes are 'pseudoeveryday life activities' (Fig. 2: the 'wings'). Students are often assigned tasks in relation to everyday life activities alone with patients, because both the students and their mentors take it for granted that these kinds of activities are routine for the students, but they are not. The students cannot act in these kinds of activities exactly as they do in everyday life. The activities are non-routine for students, because they are interacting professionally with psychiatric patients, not with family or friends. The activities are pseudoeveryday life activities. In situations characterised as pseudoeveryday life activities, students often have the opportunity both to learn to perform psychiatric nursing and to be professionally socialised, but often these situations can also be categorised as collective not-conscious disjuncture (Fig. 2: lower right quadrant). This means there is unexploited learning potential in pseudoeveryday life activities (Kragelund, 2006).

\section{An empirical example}

An unspoken rule in psychiatry is that when a patient talks about committing suicide, this should be reported immediately to more qualified members of staff.

Julie was asked by her mentor if she could have lunch with a patient in her room, because the patient was afraid that the food was poisoned. Julie agreed.

During the lunch, the patient talked about committing suicide. However, Julie did not report this to the nurse until $2 \mathrm{~h}$ later. Julie explained: 'I had the impression that I could leave the patient unsupervised without any cause for concern, and I left the room a couple of times. When I told my mentor what had happened, she became angry, because I had not told her immediately. She said that if she had known, she would not have lent the patient a pair of scissors earlier. I will remember that, because it is important' (Julie in Kragelund, 2006).

Using the Windmill model, the situation can be analysed as follows.

At the beginning of the encounter, neither Julie nor the mentor was aware that Julie was entering a non-routine situation. Both of them thought that it was an everyday task for Julie to have lunch with a patient. However, it was not. The situation was characterised as collective not-conscious disjuncture (Fig. 2: lower right quadrant). During the lunch, the situation was characterised as individual notconscious disjuncture (Fig. 2: upper right quadrant) ("I had the impression that I could leave the patient unsupervised without any cause for concern...").

In the aftermath of Julie's interaction with the patient, it became obvious to both Julie and her mentor that Julie had acted in a nonroutine situation. The situation was characterised as collective conscious disjuncture (Fig. 2: lower left quadrant).

The factors which provoked transformation from one type of disjuncture to another were the teaching and learning strategies the mentor and Julie used. Julie's strategy was telling her mentor, that the patient had talked about committing suicide, while the mentor used feedback when she became angry and told Julie off.

Julie was acting in a pseudo-everyday life activity. This gave her the opportunity both of being professionally socialised, by learning about the unwritten norm-and-rule that when a patient talks about committing suicide, this should immediately be reported to more highly trained staff, and of learning to perform nursing, by interacting with a patient, and containing a patient's projections.

\section{Discussion}

A supporting clinical learning environment is essential for student nurses' learning (Chan, 2002), and clinical practice must secure students' learning possibilities. Nevertheless, investigations show that many hospital wards do not live up to that, and that the limited time students have in clinical practice is not used effectively. The Windmill model can be used as a pedagogical tool to map student nurses' learning processes in non-routine situations when they interact with psychiatric patients (Kragelund, 2007), and it can help them use their time in clinical practice more effectively.

Even though some research shows that students prefer ad hoc rather than planned mentoring (Melrose and Shapiro, 1999) the Windmill model can be used prior to a student's interaction with a patient. A discussion based on this model can help both student and mentor identify the type of situation the student is entering. In this way, is it possible for the student to prepare for the learning process, and for what the overall content of it might be. However, these situations might not always come out as expected. Something unforeseen might happen, so a situation which might, at the start, appear to be routine for a student, can turn out to be non-routine. The student might identify disjuncture during the interaction when the patient says or does something other than what the student expected. Consequently, the student may not know how to react. Individual conscious disjuncture results. In such situations, students often make mistakes, and their acts fail (Kragelund, 2006). Using the Windmill model prior to the students' interaction with patients might prevent them from not knowing how to take care of the patients, and that might reduce their experiences of stress and not make them want to withdraw from the patients (Morrissette, 2004; Tully, 2004).

Another scenario is one where the student becomes aware of disjuncture when the mentor asks the student questions about the interaction afterwards, transforming individual not-conscious disjuncture into collective conscious disjuncture. In such a situation, the 
Windmill model can also be used after the student's interaction with a patient. The student can, either alone or together with the mentor, uncover what type of situation it was in regarding disjuncture and the overall content of the learning process. In addition, student and mentor can discuss whether or not the learning and teaching strategies they used were appropriate in relation to the student's learning. They will be able to identify whether the student's learning process was transformed from one type of disjuncture to another during the interaction, or in the discussion afterwards. On this background they can plan how they should handle a similar situation in the future in order to fully exploit the student's learning potential. This can be seen as a space where students can talk about their experiences and get feedback (Morrissette, 2004). From research it is also known that students find their relationship with mentors important (Chan, 2002; Papp et al., 2003; Saarikoski and Leino-Kilpi, 2002). A space as the suggested might be a possibility for development of a relationship between students and mentors. A similar argument according the Windmill model is, that it can be used as a tool for students and mentors to develop their professional relationship.

\section{Limitations}

The Windmill model offers a mean of understanding student nurses' learning processes from an individual perspective. That perspective can be criticised for not capturing social learning processes.

State-of-the-art build on primo 2002-ultimo 2004. It can be criticised not to include newer research. The reason why is, that my research about student nurses learning processes build on that period (Kragelund, 2006). The concepts of collective not-conscious disjuncture and pseudo-everyday life activities can be developed further. The Windmill model was developed in the field of psychiatry. I believe that it could also be applicable to other fields of nursing education, but more research has still to be done to verify this.

\section{Concluding reflections}

Using the Windmill model as a pedagogical tool can have a positive effect on students' learning. Firstly, if mentors introduce the model to students, it can be interpreted by students as a sign of interest in mentoring, an interest which some mentors are lacking (Pearcey and Elliott, 2004). Secondly, it can be seen as a way to support students in their learning, a support they do not always get (Chan, 2002; Papp et al., 2003). Thirdly, using the model can help students to learn as much as possible in a potential learning situation and to use the limited time in clinical practice effectively. As Chan found, there is a need to find ways to make students' time in clinical practice effective (Chan, 2002).

My argument according to that is, that there is the potential to maximise the effectiveness of student nurses' clinical training if the Windmill model is used as a tool. Firstly, using the model can help students and their mentors identify learning situations which at first sight are not recognised as such, but which, following careful analysis, appear to be non-routine for students, and therefore provide learning potential. Secondly, using the model can help students and mentors identify the content of the learning processes. This awareness will afford both of them the opportunity to select those tasks which students can usefully perform in order to achieve the objectives of their clinical placement, to develop their professionalism and to become professionally socialised.

\section{Acknowledgements}

I would like to thank Claudia Gian Rossi for her editing assistance throughout the writing process, and Associate Professor Venka Simovska and Professor Julie Scholes for their constructive feedback on earlier versions of this article. Although I have had some assistance in writing this article, any errors and omissions that may remain are mine alone.

\section{References}

Chan, D.S.K., 2002. Associations between students' learning outcomes from their clinical placement and their perceptions of the social climate of the clinical learning environment. International Journal of Nursing Studies, 39. Elsevier Science Ltd, pp. 517-524.

Heller, A., 1970/1984. Everyday Life. Routledge \& Kegan Paul, London.

Jarvis, P., 1987. Adult Learning in the Social Context. Croom Helm Ltd., London.

Jarvis, P., 1992a. Paradoxes of Learning, on Becoming an Individual in Society. JosseyBass Publishers, San Francisco.

Jarvis, P., 1992b. Reflective practice and nursing. Nurse Education Today, 12 (3) Elsevier Ltd, pp. 174-181.

Jarvis, P., 1999. The Practitioner-researcher - Developing Theory from Practice. JosseyBass Publishers, San Francisco.

Jarvis, P., 2005. Towards a philosophy of human learning. In: Jarvis, P., Parker, S. (Eds.) Human Learning. A Holistic Approach. Routledge \& Kegan Paul, London. New York.

Kragelund, L., 2006. Uddannelse til professionsbachelor i sygepleje - En kvalitativ undersøgelse af sygeplejestuderendes læreprocesser under klinisk uddannelse psykiatri. Danmarks Pædagogiske Universitets Forlag, København.

Kragelund, L., 2007. Kategoriseringsmodel for sygeplejestuderendes læreprocesser - et arbejdsredskab til sygeplejestuderende og deres kliniske vejledere. Danmarks Pædagogiske Universitets Forlag, København.

Lauder, W., Reynolds, W., Smith, A., Sharkey, S., 2002. A comparison of therapeutic commitment, role support, role competency and empathy in three cohorts of nursing students. Journal of Psychiatric and Mental Health Nursing, 9. Blackwel Science Ltd, pp. 483-491.

Melrose, S., Shapiro, B., 1999. Students' perceptions of their psychiatric mental health clinical nursing experience: a personal construct theory exploration. Journal of Advanced Nursing, 30. Blackwell Science Ltd, pp. 1451-1458.

Ministry of Education, 2001. Departmental Order of Nursing Education, no. 232 30.03.01. Ministry of Education, Copenhagen.

Morrissette, P.J., 2004. Promoting psychiatric student nurse well-being. Journal of Psychiatric and Mental Health Nursing, 11. Blackwell Publishing Ltd, pp. 534-540

Munnukka, T., Pukuri, T., Linnainmaa, P., Kilkku, N., 2002. Integration of theory and practice in learning mental health nursing. Journal of Psychiatric and Mental Health Nursing, 9 (1). Blackwell Science Ltd, pp. 5-14.

Papp, I., Markkanen, M., von Bonsdorff, M., 2003. Clinical environment as a learning environment: student nurses' perceptions concerning clinical experience. Nurse Education Today, 23 (4). Elsevier Science Ltd, pp. 262-268.

Pearcey, P.A., Elliott, B.E., 2004. Student impressions of clinical nursing. Nurse Education Today, 24. Elsevier Ltd, pp. 382-387.

Rungapadichy, D.M., Madill, A., Gough, B., 2004. Mental health nurses' perception of the role of the mental health nurse. Journal of Psychiatric and Mental Health Nursing, 11. Blackwell Publishing Ltd, pp. 714-724.

Saarikoski, M., Leino-Kilpi, H., 2002. The clinical learning environment and supervision by staff nurses: developing the instrument. International Journal of Nursing Studies, 39. Elsevier Science Ltd, pp. 259-267.

Tully, A., 2004. Stress, sources of stress and ways of coping among psychiatric nursing students. Journal of Psychiatric and Mental Health Nursing, 11(1). Blackwell Publishing Ltd, pp. 43-47. 